\title{
Effect of drought on gas exchange and chlorophyll fluorescence of groundnut genotypes
}

\section{K. Manojkumar*}

Department of Crop Physiology, Tamil Nadu Agricultural University, Coimbatore - 641003 (Tamil Nadu), India

\section{S. Vincent}

Department of Crop Physiology, Tamil Nadu Agricultural University, Coimbatore - 641003 (Tamil Nadu), India

\section{Raveendran}

Department of Plant Biotechnology, Tamil Nadu Agricultural University, Coimbatore - 641003 (Tamil Nadu), India

\section{R. Anandham}

Department of Agricultural Microbiology, Tamil Nadu Agricultural University, Coimbatore - 641003 (Tamil Nadu), India

\section{Babu Rajendra Prasad}

Department of Crop Physiology, Tamil Nadu Agricultural University, Coimbatore - 641003 (Tamil Nadu), India

\section{A. Mothilal}

Regional Research Station, Tamil Nadu Agricultural University, Virudhachalam - 606001 (Tamil Nadu), India

\section{S. Anandakumar}

Department of Agricultural Microbiology, Tamil Nadu Agricultural University, Coimbatore 641003 (Tamil Nadu), India

${ }^{*}$ Corresponding author. Email: manoagri900@gmail.com

\section{Article Info}

https://doi.org/10.31018/

jans.v13i4.3145

Received: October 27, 2021

Revised: December 3, 2021

Accepted: December 7, 2021

\section{How to Cite}

Manojkumar, K. et al. (2021). Effect of drought on gas exchange and chlorophyll fluorescence of groundnut genotypes. Journal of Applied and Natural Science, 13(4), 1478 - 1487. https://doi.org/10.31018/jans.v13i4.3145

\section{Abstract}

Drought is one of the major threats to groundnut productivity, causing a greater loss than any other abiotic factor. Water stess conditions alter plant photosynthetic activity, impacting future growth and assimilating mobilization towards sink tissues. The purpose of this study was to investigate how drought impacts the photosynthesis of plants and its links to drought tolerance. The influence of reproductive stage drought on photosynthetic activity and chlorophyll fluorescence of groundnut is well studied. Theexperiment was conducted in Kharif 2019 (Jul-Sep), where recent series in groundnut genotypes (60 nos) sown under rainfed conditions and water stress was created by withholding irrigation for 20 days between 35-55 days after sowing in the field to simulate drought conditions. Imposition of water deficit stress reduced PS II efficiency, which significantly altered the photosynthetic rate in the leaf. Observation of gas exchange parameters viz., photosynthetic rate, stomatal conductance and transpiration rate after 20 days of stress imposition revealed that of all 60 genotypes, 20 genotypes (VG 17008, VG 17046VG 18005, VG 18102, VG 18077, VG 19572, VG 19709, VG 18111, VG19561, VG19576, VG 19620, VG 19681, VG 19688, etc.,) had better Photosynthetic rate, Stomatal conductance. Similarly, PS II efficiency analyzed through fluorescence meter revealed that among the 60 and all the genotypes given above recorded higher value in Fv/Fm. Results obtained from Cluster analysis and PCA confirmed that photosynthetic rate and Fv/Fm is useful parameter in screening adapted cultivars under drought stress. These findings lay the groundwork for a future study to decipher the molecular pathways underpinning groundnut drought resistance.

Keywords: Chlorophyll fluorescence, Drought stress, Groundnut, Photosynthesis

\section{INTRODUCTION}

Groundnut (Arachis hypogea L.) is a valuable oilseed crop with $44-56 \%$ of oil content, which is used as a staple oil in most parts of the country. It is the second most important protein source after soybean, with 22$30 \%$ protein on a dry seed basis (Savage and Keenam 1994). Groundnut is primarily a rain-fed crop grown in 
19.3 million hectares of land across 82 countries. More than half of the producing area is in arid and semi-arid regions. Abiotic stresses, such as heat and drought, are major environmental factors that frequently limit crop growth and productivity (Barnabás et al. 2008) and Sita et al. (2008). Drought accompanied by high temperature is expected to become more common in the near future (IPCC 2014), emphasizing the importance of investigating crop responses to heat and drought stresses (Zandalinas et al., (2017). The estimated increase in mean temperature of $1.3-6{ }^{\circ} \mathrm{C}$ in future climates (Houghton et al., (2001), as well as an increase in temperature variability, will exacerbate these problems (Wheeler et al., (2000)). Groundnut is frequently subjected to drought stress of varying durations and intensities as a result of climate change. Groundnut yields in India ranged from 550 to $1100 \mathrm{~kg} /$ ha over the years, resulting in total production of 4.3 to 9.6 million tonnes. Drought stress has emerged as a serious problem in approximately 45 percent of agricultural areas and one of the most significant global productivity constraints (Heinemann et al., 2017; Todaka et al., 2015). The most promising approach is to develop better cultivars that can tolerate a wide range of abiotic stress conditions, including drought, floods, and high temperatures. Drought-induced morphological and physiological alterations can be utilized to discover drought-resistant genotypes or develop novel crop kinds for increased drought productivity (Nam et al., 2001). Plant responses to drought stress are influenced by the severity and length of the stress, as well as the plant species and stage of development (Parameshwarappa and Salimath, 2010). Plants constrict their stomata to prevent more water loss when they are stressed by drought. Drought stress reduces the net photosynthetic rate by lowering internal $\mathrm{CO} 2$ concentration (Ci) and inhibiting ribulose-1, 5-bisphosphate carboxylase/oxygenase enzyme activity and ATP generation (Dulai 2006). Reduced photosynthetic inhibition under drought stress is critical for drought resistance (Zlatev and Yordanov, 2004). Many crop genotypes, including Zea mays (Ashraf et al., 2007), Brassica napus L. (Kauser et al., 2006), and mungbean, have been studied to see how drought stress affects $\mathrm{CO} 2$ absorption rate $(\mathrm{A})$ and transpiration rate (E) (Ahmed et al., 2002). Drought stress reduces the electron transport rate (ETR) and the effective quantum yield of photosystem II photochemistry $(Y)$ and reduces photosystem efficiency (Fv/Fm) (Ahmed et al., 2002). The Fv/Fm ratio is a metric that may be used to diagnose PSIl damage and possibly photoinhibition (Ahmed et al., 2002). Under drought stress, changes in the proportion of photochemical and energy-dependent quenching cause changes in fluorescence kinetics (Zlatev and Yordanov, 2004). The chloroplast thylakoid membrane fluorescence is frequently utilized as a very sensitive intrinsic indicator of the photosynthetic response in photosystem II (Ahmed et al., 2002). Damage to light response systems in photosynthetic processes under drought stress may be determined by analyzing chlorophyll fluorescence and measuring the Fv/Fm ratio. The responses of numerous photosynthesis-related parameters, as well as the function of specific variables in photosynthetic damage, were investigated in this work. We investigated the effects of drought stress on photosynthesis and chlorophyll fluorescence in 60 genotypes to find a rapid and simple approach for screening groundnut genotypes for drought resistance.

\section{MATERIALS AND METHODS}

\section{Plant materials}

The details of groundnut genotypes taken are given in Table 1

\section{Field trial}

Field trials were conducted during the post rainy season in March 2019. The soil was red sandy loam with slightly acidic to alkaline $\mathrm{pH}$, poor in the water holding capacity, low in $\mathrm{N}$, medium in $\mathrm{P}$ and $\mathrm{K}$ and micronutrient zinc and boron. The water holding capacity of this field is 1.9 "/ft. The bulk density is $1.35 \mathrm{~g} \mathrm{~cm}-3$ for the 0 $15 \mathrm{~cm}$ soil layer and $1.45 \mathrm{~cm}-3$ for the $105-120 \mathrm{~cm}$ soil layer, while the accessible soil water till $120 \mathrm{~cm}$ depth was $165 \mathrm{~mm} 26$. Before sowing, 18 kilograms $\mathrm{N}$ ha 1 and $20 \mathrm{~kg} P$ ha 1 di-ammonium phosphate were applied. Plants were successively cultivated under rainfed circumstances. Hand weeding was used to keep the plots free of weeds.

\section{Chlorophyll fluorescence}

The fluorescence meter (Plant PAM-210 (Teaching PAM), Heinz Walz, Germany) was used to quantify chlorophyll florescence. The essential fluorescence characteristics were measured: Fo (initial fluorescence), Fv (variable fluorescence), Fm (maximal fluorescence), and the ratio of $\mathrm{Fv} / \mathrm{Fm}$.

$\mathrm{Fv} / \mathrm{Fm}=$ Variable fluorescence / Maximum fluorescence Eq.1

The proportion of quantum yield in response to a high degree of photosynthesis is depicted by the Fv/Fm ratio

\section{Leaf gas exchange parameters}

An innovative portable photosynthesis system was used to monitor gas exchange characteristics such as photosynthetic rate, transpiration rate, and stomatal conductance (LI-6400 XT, Licor Inc, Nebraska, USA). The measurements were taken from 10 a.m. to 12 p.m. on a bright sunny day with more than 1000 mol photons $\mathrm{m}^{-2} \mathrm{~s}^{-1}$ of photosynthetically active radiation and no effects of photo-inhibition. The top of the fully extended leaf was clamped inside the leaf chamber and held per- 
Table 1. Details of genotypes used in this study

\begin{tabular}{cccccccc}
\hline S. No & Genotypes & S. No & Genotypes & S. No & Genotypes & S. No & Genotypes \\
\hline 1 & VG 17003 & 16 & VG 17050 & 31 & VG 18098 & 46 & VG 19572 \\
2 & VG 17006 & 17 & VG 17051 & 32 & VG 18100 & 47 & VG 19576 \\
3 & VG 17007 & 18 & VG 18002 & 33 & VG 18102 & 48 & VG 19620 \\
4 & VG 17008 & 19 & VG 18049 & 34 & VG 18103 & 49 & VG 19654 \\
5 & VG 17009 & 20 & VG 18055 & 35 & VG 18110 & 50 & VG 19681 \\
6 & VG 17010 & 21 & VG 18058 & 36 & VG 18111 & 51 & VG 19688 \\
7 & VG 17013 & 22 & VG 18062 & 37 & VG 19534 & 52 & VG 19709 \\
8 & VG 17016 & 23 & VG 18076 & 38 & VG 19539 & 53 & VG 19719 \\
9 & VG 17017 & 24 & VG 18077 & 39 & VG 19541 & 54 & VG 19720 \\
10 & VG 17018 & 25 & VG 18081 & 40 & VG 19542 & 55 & VG 19721 \\
11 & VG 17019 & 26 & VG 18089 & 41 & VG 19543 & 56 & VG 19726 \\
1 & VG 17022 & 27 & VG 18090 & 42 & VG 19545 & 57 & VG 19732 \\
13 & VG 17023 & 28 & VG 18094 & 43 & VG 19546 & 58 & VG19535 \\
14 & VG 17037 & 29 & VG 18096 & 44 & VG 19548 & 59 & VRI 8 \\
15 & VG 17046 & 30 & VG 18097 & 45 & VG 19561 & 60 & VRI 2 \\
\hline
\end{tabular}

pendicular to incident light, with computed values recorded. The instrument maintained a constant $\mathrm{CO}_{2}$ flux to the leaf chamber, which was maintained at ambient concentration. Relative humidity was maintained at a steady level equal to the ambient relative humidity to simulate a condition similar to that of ambient air. The photosynthetic rate expressed as $\mu \mathrm{mol} \mathrm{CO} 2 \mathrm{~m}^{-2} \mathrm{~s}^{-1}$, stomatal conductance and transpiration rate expressed as $\mathrm{mmol} \mathrm{H}_{2} \mathrm{O} \mathrm{m} \mathrm{m}^{-2}$. The equipment maintained a continuous $\mathrm{CO}_{2}$ input to the leaf chamber, keeping the concentration at ambient. The relative humidity was kept constant at the same level as the ambient relative humidity to imitate ambient air conditions. Units of those parameters Viz., Photosynthetic rate (mol CO2 $\left.\mathrm{m}^{-2} \mathrm{~s}^{-1}\right)$, stomatal conductance ( $\mathrm{mmol} \mathrm{H} 2 \mathrm{O} \mathrm{m}^{-2} \mathrm{~s}^{-1}$ ), and transpi-

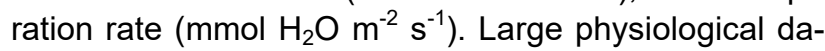
tasets obtained from plants grown under drought and well-watered circumstances are still difficult to evaluate and comprehend. For such assessments, a variety of methodologies and statistical models have been offered. In phenotypic screening for drought tolerance, correlation analysis, PCA, and clustering are considered to be good methods for analysing the correlations between the parameters and their principal components. (Sun et al., (2013), Nazari and Pakniyat (2010).

\section{Chlorophyll Index (SPAD value)}

SPAD readings were taken with a chlorophyll meter (SPAD 502) designed by the Soil Plant Analytical Development (SPAD) department of Minolta, Japan. The Minolta SPAD-502 monitors chlorophyll concentration as a ratio of light transmittance at 650 and $940 \mathrm{~nm}$ wavelengths. Five readings were obtained from each treatment in each replication, and the average value was estimated following the method given by Minolta (1989) and Monje and Bughree (1993).

\section{Soil moisture and weather data collection}

Soil moisture was measured at planting using the gravimetric method. Rainfall, relative humidity $(\mathrm{RH})$, maximum and minimum air temperature, evaporation (E0), and solar radiation (Table 2 ) were measured daily by a meteorological station 50 meters away from the study field from planting to harvest. The experiment was carried out in a transparent roofed open-sided greenhouse.

\section{Statistical analysis}

The analysis of variance (ANOVA) was used to do statistical studies on the data. SPSS-20.0 was used to assess the significant differences between the means of stress treatments using the LSD (least significant difference) test at $p$ 0.05. Python software was used to perform principal component analysis (PCA) and cluster analysis. The first two principal components were utilized to generate the PCA-biplot and the probable genotype connections. PC1 describes the stomatal conductance (SC), transpiration rate (TrR), photosynthetic rate $(\mathrm{Pn})$, Leaf temperature (Lt). In PC2 Chlorophyll fluorescence and (SPAD).

\section{RESULTS AND DISCUSSION}

Drought stress has been a key environmental element in lower agricultural output and food safety across the world. The plant's perception of drought stress from its 
Table 2. Weather data for the year 2019

\begin{tabular}{|c|c|c|c|c|c|c|c|c|}
\hline \multirow{2}{*}{$\begin{array}{l}\text { Month } \\
(2019)\end{array}$} & \multicolumn{3}{|c|}{ Temperature $\left({ }^{\circ} \mathrm{C}\right)$} & \multicolumn{3}{|c|}{ Relative humidity (\%) } & \multirow{2}{*}{$\begin{array}{l}\text { Evaporation } \\
(\mathrm{mm})\end{array}$} & \multirow{2}{*}{$\begin{array}{l}\text { Rainfall } \\
(\mathrm{mm})\end{array}$} \\
\hline & Max & Min & Mean & Max & Min & Mean & & \\
\hline March & 39.6 & 29.0 & 34.3 & 79 & 50 & 64 & 134.0 & 00.3 \\
\hline April & 46.2 & 31.2 & 38.0 & 86 & 64 & 75 & 96.5 & 00.1 \\
\hline May & 45.7 & 33.0 & 39.5 & 91 & 69 & 80 & 105.4 & 00.8 \\
\hline June & 39.2 & 29.5 & 34.2 & 89 & 67 & 78 & 102.0 & 00.2 \\
\hline Total & & & & & & & 109.47 & 0.35 \\
\hline
\end{tabular}

surroundings changes geographically and temporally at numerous scales. Drought impacts membrane lipids, photosynthetic reactions, and yield (Lauriano et al., 2000). A lack of water affects the thylakoid membrane electron transport, phosphorylation, carboxylation, and photosynthesis. In water-stressed plants, changes in lipid concentration and composition are prevalent, which increases membrane permeability. Damage and membrane rupture occurs as a result, as well as a decrease in photosynthesis. The plant's resilience to stress will be determined by maintaining membrane integrity during drought circumstances. Although groundnut is a drought-tolerant crop, particularly during the mid- or late-season of crop growth, that considerably lowers different metabolic activities of the crop, owing to a lack of appropriate water supply to active tissue and final stomata closure (Devi et al., 2009). During water shortage stress, Kalariya et al. (2013) found an $11-30 \%$ drop in net photosynthesis in groundnut. Apart from stomatal limitation, the fast breakdown of thylakoid membranes in groundnut was also blamed for limiting photosynthetic performance under severe water shortage stress (Lauriano et al., 2000). Carbon transfer from source to sink tissue and subsequent metabolism is affected by a reduced rate of photosynthesis in water deficiency stress.

\section{Effect of drought on chlorophyll fluorescence}

Chlorophyll fluorescence measurements may provide a useful measure of the photosynthetic performance of plants. Particularly, fluorescence can give insights into the ability of a plant to tolerate environmental stresses and into the extent to which those stresses have damaged the photosynthetic apparat. In the present study, chlorophyll fluorescence results indicated that the mean value of all the genotypes was less in drought than in control. Drought decreased the Fv/Fm ratio over the control. The groundnut genotypes VG 18005 (0.70) and VG 18097(0.69) had significantly increased Fv/Fm ratio while Fv/Fm was decreased in VGG 17046(0.12) compared to other groundnut genotypes under stress conditions (Fig 1). Vurayai et al. (2010) discussed that water stress reduced chlorophyll fluorescence and the reduction was more pronounced in plants stressed during the reproductive stage and less pronounced in plants stressed during the vegetative stage. There was a decline in chlorophyll fluorescence (estimated from dark-adapted Fv/Fm ratio). This is due to the downregulation of photosystem II activity, which indicates damage in the functionality of the photosynthetic apparatus. Similar results of plants lowering their Fv/Fm under water stress and then recovering after re-watering were obtained in kidney beans (Miyashita et al., 2005) and tobacco (Galle et al., 2009). Chloroplast membrane gets disrupted under stress conditions by direct or indirect effects like lipid peroxidation (Khattak et al. 2006; Djanaguiraman et al., 2009) and inhibition of biosynthesis or degradation of chlorophyll (Huseynova 2012) due to ROS induced oxidative stress (Prasad et al., 1999) or disorganisation of chloroplasts due to photooxidation. Higher chlorophyll content in control plants compared with plants exposed to drought stress might be due to

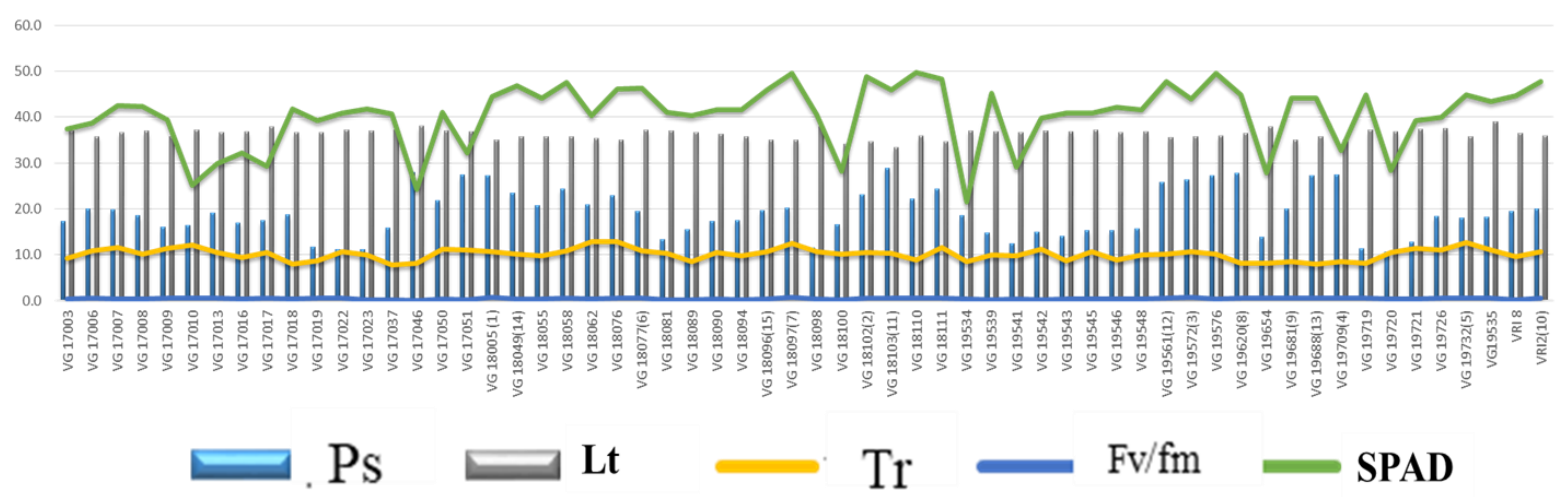

Fig. 1. Effect of drought on gas exchange and chlorophyll fluorescence (Ps- Photosynthetic rate, Sc- stomatal conductance, $\mathrm{Lt}$-leaf temperature, $\mathrm{Tr}$-Ttranspiration rate, Fv /Fm-Chlorophyll fluorescence, SPAD) 
quenching of ROS by antioxidant enzymes; otherwise, ROS would have destroyed the chlorophyll pigments (Thomas et al., 2003). Chlorophyll fluorescence measurements may provide a useful measure of the photosynthetic performance of plants. Particularly, fluorescence can give insights into the ability of a plant to tolerate environmental stresses and into the extent to which those stresses have damaged the photosynthetic apparatus (Maxwell and Jonhson, 2000).

\section{Effect of drought on gas exchange}

The Fv/Fm ratio is the prime factor that decides the photosynthetic rate because the increased proportion of PSII reaction centres was highly declined during the drought stress due to an increase in ROS accumulation (Miller et al., 2010). The photosynthetic rate was highly reduced under drought stress in the reproductive stage. High significant variation was recorded between treatments and genotypes. Similar to the photosynthetic rate, stomatal conductance followed the same trend. Genotypes VG 180102 (28.99) and VG 19572 (24.53) performed better, while in VG 17022 (11.16) the photosynthetic rate was decreased than the other genotypes under stress conditions (Fig. 1). The stomatal conductance was significantly increased in VG 19732 (0.60) and VG 18102 (0.53) and decreased in VG 17003 (0.19) than the other genotypes under stress conditions (Fig. 2). Similar to our findings, reduction in photosynthetic rate, stomatal conductance, Fv/Fm ratio were observed in soybean plants grown under drought stress (Djanaguiraman et al., 2009). Transpiration rate is an important trait for gas exchange in plants. Irrespective of the genotypes, the stressed plants showed 40 per cent reduction in transpiration rate than the control. The transpiration rate was comparatively higher in VG 17050 (12.8) and VG 17018 (12.5). VG 18102 (7.9) showed decreased transpiration rate under drought stress (Fig 1). Reddy et al. (2003) reported that moisture stress reduced canopy photosynthesis due to reduced stomatal conductance. As moisture stress increases, stomata start closing as a mechanism to reduce transpiration. As a consequence, the entry of carbon dioxide is also reduced. The decrease in conductance of mesophyll cells due to moisture stress results in low conductance of carbon dioxide and a reduction in photosynthesis and stomatal conductance. Vurayai et al. (2010) discussed that decreased stomatal conductance results in lower net carbon dioxide assimilation rate, lower intercellular carbon dioxide and lower chloroplastic carbon dioxide tension resulted in reduced photosynthetic efficiency. Plants stressed during the vegetative stage completely recovered their stomatal conductance after re-watering. Recovery of stomatal conductance may result in increased carbon dioxide diffusion into the leaves to attain higher photosynthetic rates. During drought stress, the leaf temperature was gradually increased in VG 17050 (38.06) and VG 18081(38.93) genotypes, while the decreasing trend

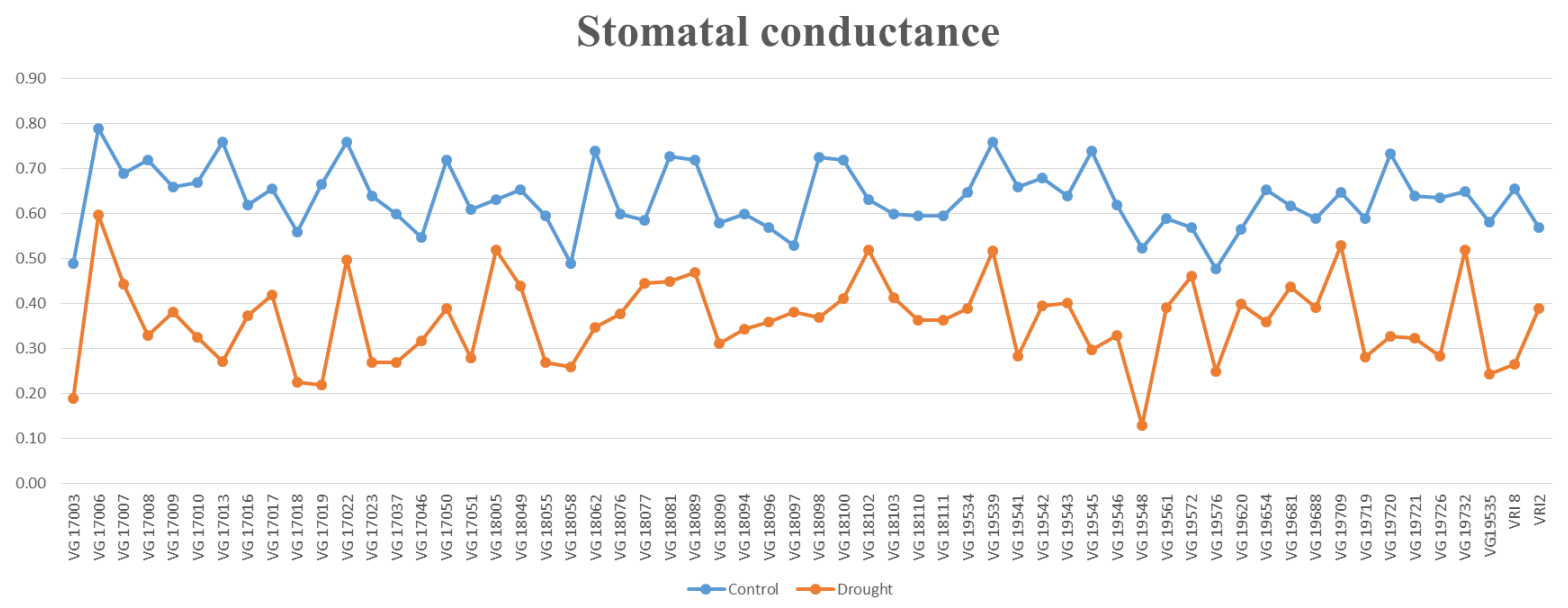

Fig. 2. Effect of drought on stomatal conductance

Table 3. Correlation between gas exchange parameters and chlorophyll fluorescence

\begin{tabular}{lllllll}
\hline Char & Ps & SC & Lt & Tr & Fv/Fm & SPAD \\
\hline Ps & 1 & 1 & & & & \\
Sc & 0.20 & $0.36^{*}$ & 1 & & & \\
Lt & $0.64^{* *}$ & 0.16 & 0.29 & 1 & & \\
Tr & 0.33 & 0.46 & 0.34 & 0.230 & 1 & 1 \\
Fv/Fm & $0.77^{* *}$ & 0.21 & 0.39 & 0.190 & $0.36^{*}$ & \\
SPAD & $0.46^{*}$ & 0.21 & & & \\
\hline
\end{tabular}

Ps- Photosynthetic rate, Sc- stomatal conductance, Lt -leaf temperature, $\mathrm{Tr}$-Ttranspiration rate, Fv/Fm-Chlorophyll fluorescence, SPAD 
was observed in VG 18102 (33.06) and VG 19709 (34.01) when compared to other genotypes (Fig. 1). Lourtie et al.(1995) reported that water deprivation for many days induced mild water stress on maize seedlings, resulting in an increase in leaf temperature and a loss in biomass). Because stomatal aperture and leaf area influenced the rate of both photosynthesis and transpiration, biomass formation is inextricably tied to transpiration (Collins et al., 2008). Stomatal regulation is thought to be closely connected to plant drought resistance. As a result, we hypothesised that an increase in leaf temperature-driven solely by stomatal closure is only a surface phenomenon; in fact, water stress resulted in stomatal closure, which reduced water loss and hence boosted biomass growth. Plant biomass accumulation in response to water stress is probably connected to leaf temperature fluctuation, predicting genotype biomass performance.

SPAD chlorophyll value is expressed as chlorophyll index, and there was a decreasing trend observed (Fig 1). Water stressed genotypes recorded less chlorophyll index than control. G genotypes VG 19572 (49.6) and VG 18103 (49.8) recorded higher values during drought and a huge decline in the chlorophyll index was observed in VG 17046 (24.2) and VG 18062 (21.5) (Fig 1). Awal and Ikeda (2002) described that limiting the water supply induced faster degradation of chlorophyll pigments. Moreover, stressed plants failed to take up sufficient water and mineral nutrients from the soil and many biochemical activities were arrested, resulting in the reduction of leaf chlorophyll concentrations. Batra et al. (2014) reported that stress induced chlorophyll loss in Vigna radiata could be accounted for light harvesting chlorophyll protein molecules in thylakoid membrane. The significant reduction in chlorophyll during drought periods may be due to photoinhibition was reported by Dias et al. (2010) in Phaseolus vulgaris, Zlat-

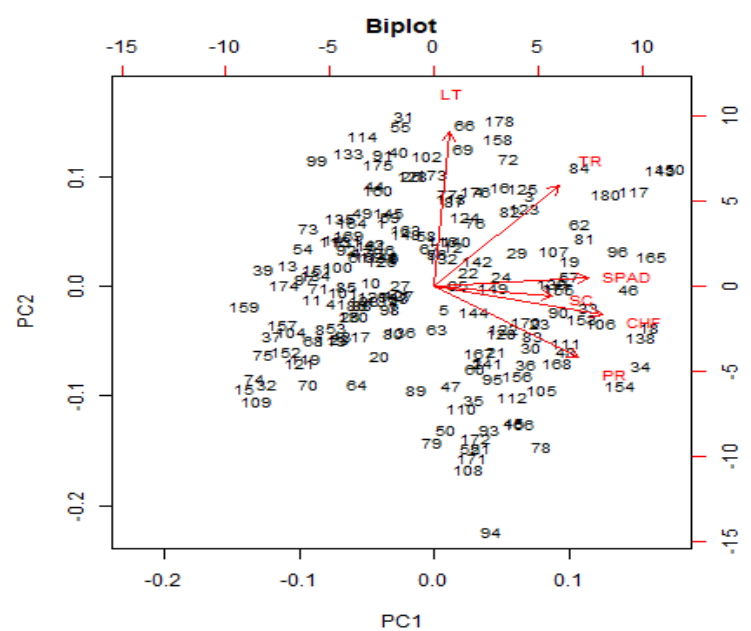

ev, 2009 in wheat and Zlatev and Yordanov (2004) in the bean. But, after re-watering, the chlorophyll inhibition signals induced by abscisic acid or proline and any other barriers might be removed, allowing the chlorophyll concentration to increase again. Yolcu et al. (2021) explained that higher root length and volume leading to excess uptake of nutrients from soil corresponds to rapid chlorophyll molecules in leaves and to regain foliar water status during stress. These results were in accordance with our present study.

The correlation result shows that all the parameters in the model were positively correlated. Among those parameters, the correlation between PS and leaf temperature, Ps and $\mathrm{Fv} / \mathrm{Fm}$ was found to be significant at $1 \%$ level of significance (Table 3). Meanwhile, the correlation between Ps and SPAD, Sc and Lt, Fv/Fm and SPAD were found to be significant at $5 \%$ level of significance. The results evidenced that there was a higher overlapping prevailed between $\mathrm{Ps}$ and $\mathrm{Sc}$ and $\mathrm{Ps}$ and $\mathrm{Fv} / \mathrm{Fm}$, which has coefficient of 0.64 and 0.77 , respectively (Table 2).

Biplot analysis (Fig. 3) for Gas exchange and chlorophyll fluorescence traits variation in groundnut genotypes imposed to drought stress were observed based on the discrimination of the data. The first two principal components (PC) showed $74.92 \%$ of the variance in the data set. PC1 describes $32.49 \%$ of the variance and PC2 describes $32.49 \%$ of the variance. PC1 describes the stomatal conductance (SC), transpiration rate $(\operatorname{TrR})$, photosynthetic rate $(\mathrm{Pn})$, Leaf temperature (Lt). In PC2 Chlorophyll fluorescence, SPAD) meanwhile, the other principle compounds (PC3, PC4, PC5 and PC6) showed negligible variations in the model (Table 4). According to Khodarahmpour et al. (2011), genotypes with higher PCA1 and lower PCA2 scores produced high yields (stable cultivars), while genotypes with lower PCA1 and higher PCA2 scores produced

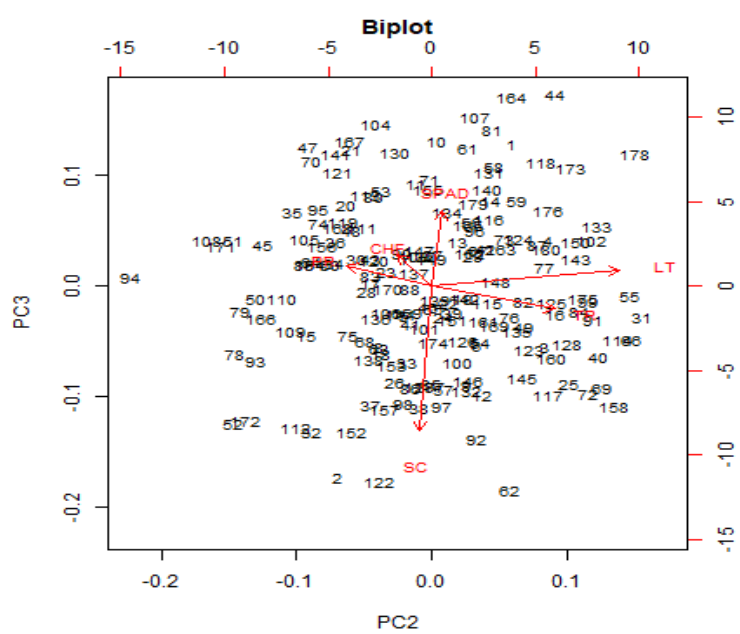

Fig. 3. Biplot drawn based on the first and second components obtained from principal component (Ps- Photosynthetic rate, Sc-stomatal conductance, Lt-leaf temperature, Tr-Ttranspiration rate, FV /Fm-Chlorophyll fluorescence, SPAD) 
Manojkumar, K. et al. / J. Appl. \& Nat. Sci. 13(4), 1478 - 1487 (2021)

Table 4. Eigen value and vectors of principal component analysis for gas exchange parameters and chlorophyll fluorescence

\begin{tabular}{lllllll}
\hline Principal compound & PC1 & PC2 & PC3 & PC4 & PC5 & PC6 \\
\hline Proportion of Variance & 0.34 & 0.20 & 0.15 & 0.12 & 0.10 & 0.09 \\
Cumulative Proportion & 0.34 & 0.54 & 0.69 & 0.80 & 0.91 & 1.00 \\
EigenValues & 2.05 & 1.20 & 0.87 & 0.71 & 0.62 & 0.56 \\
Ps & 0.45 & -0.35 & 0.12 & -0.58 & -0.25 & -0.51 \\
Sc & 0.37 & -0.05 & -0.85 & -0.12 & 0.32 & 0.14 \\
Lt & 0.05 & 0.77 & 0.10 & -0.60 & 0.03 & 0.19 \\
Tr & 0.39 & 0.50 & -0.14 & 0.51 & -0.37 & -0.43 \\
Fv/Fm & 0.52 & -0.14 & 0.19 & 0.09 & -0.40 & 0.71 \\
SPAD & 0.48 & 0.04 & 0.44 & 0.18 & 0.73 & -0.07 \\
\hline
\end{tabular}

Ps- Photosynthetic rate, Sc- stomatal conductance, Lt -leaf temperature, Tr -Ttranspiration rate, Fv /Fm-Chlorophyll fluorescence, SPAD

poor yields (unstable cultivars) (unstable cultivars). Khodarahmpour et al. (2011) utilised a PCA display to identify drought-tolerant genotypes in maize, and Mohammadi et al. (2011) employed one in wheat. The correlation analysis was supported by the results of the biplot graph. The findings of this study are in line with those of Nouri et al. (2011), who found that PCA was a superior strategy to correlation analysis for identifying higher yielding genotypes in both normal and stressed settings. PCA and biplot analysis have also been demonstrated to be effective for identifying resistant genotypes (Nouri et al., 2011; Golabadi et al., 2006).

Heat map and hierarchical clustering for gas exchange parameters and chlorophyll fluorescence under normal irrigation and drought stress conditions in 60 groundnut genotypes after 20 days of treatment. Clustering analysis of groundnut genotypes (left) revealed two major groupings, with group a representing 60 genotypes grown with normal irrigation and group b representing genotypes grown under drought conditions. The clustering analysis of various factors (top) revealed two significant groups: group I contains gas exchange parameters viz., photosynthetic rate, stomatal conductance, transpiration rate, leaf temperature and group II includes the other two parameters viz., chlorophyll fluorescence and SPAD values, whereas group I associated with Photosynthetic efficiency of groundnut genotypes during drought.

A heatmap was created using physiological and morphological measures to determine the important characteristics for measuring drought tolerance (Liu et al., 2015). As shown in Fig. 4, the Gas exchange parameters and Chlorophyll fluorescence of the 60 genotypes grown under either drought treatment or normal irrigation conditions (control) were employed for hierarchical (row) clustering. The 60 genotypes were grouped into the group a when grown under well-watered conditions, but the identical set of 60 genotypes clustered into group $b$ when grown under drought conditions. This clear clustering demonstrates that in comparison to control conditions, drought stress treatment alters all the parameters for each groundnut genotype. Hierarchical clustering analysis of the heatmap also indicated that Gas exchange parameters and Chlorophyll fluorescence could cluster the 60 genotypes into two distinct groups (top of Fig. 4 group I, II). The photosynthetic character and chlorophyll fluorescence parameters, which reflect relative long-term response to abiotic stress mainly drought, were clustered together (top of Fig. 4, group I) and were consistently different between the control (Fig. 4, group a) and the drought treatment groups (Fig. 4, group b). Thus, morphological traits do not appear to closely correlate with drought tolerance in groundnut. The five yield parameters- photosynthetic rate, stomatal conductance, transpiration rate, and Leaf temperature were clustered in to group I, where all 60 genotypes showed decreased photosynthetic rate, stomatal conductance, transpiration rate, and Leaf temperature under drought treatment (Fig. 4). In general, all 60 genotypes showed a decreased rate of photosynthesis and chlorophyll fluorescence under drought treatment. A heatmap is a visual method that can be used to explore complex associations between multiple parameters collected from various treatments. It is often useful to combine heatmap with hierarchical clustering, which is a way of arranging items in a hierarchy based on the distance or similarity between them. Despite its benefits, heatmap analysis (Fig. 4) could not identify the significant differences between the genotypes in this study. Pn, gs, Tr, and chlorophyll fluorescence were positively associated with the control treatment (well-watered) group among the six physiological parameters.

\section{Conclusion}

The study on drought resistance of 60 groundnut genotypes indicated that $\mathrm{Fv} / \mathrm{Fm}$, photosynthetic rate, sto- 


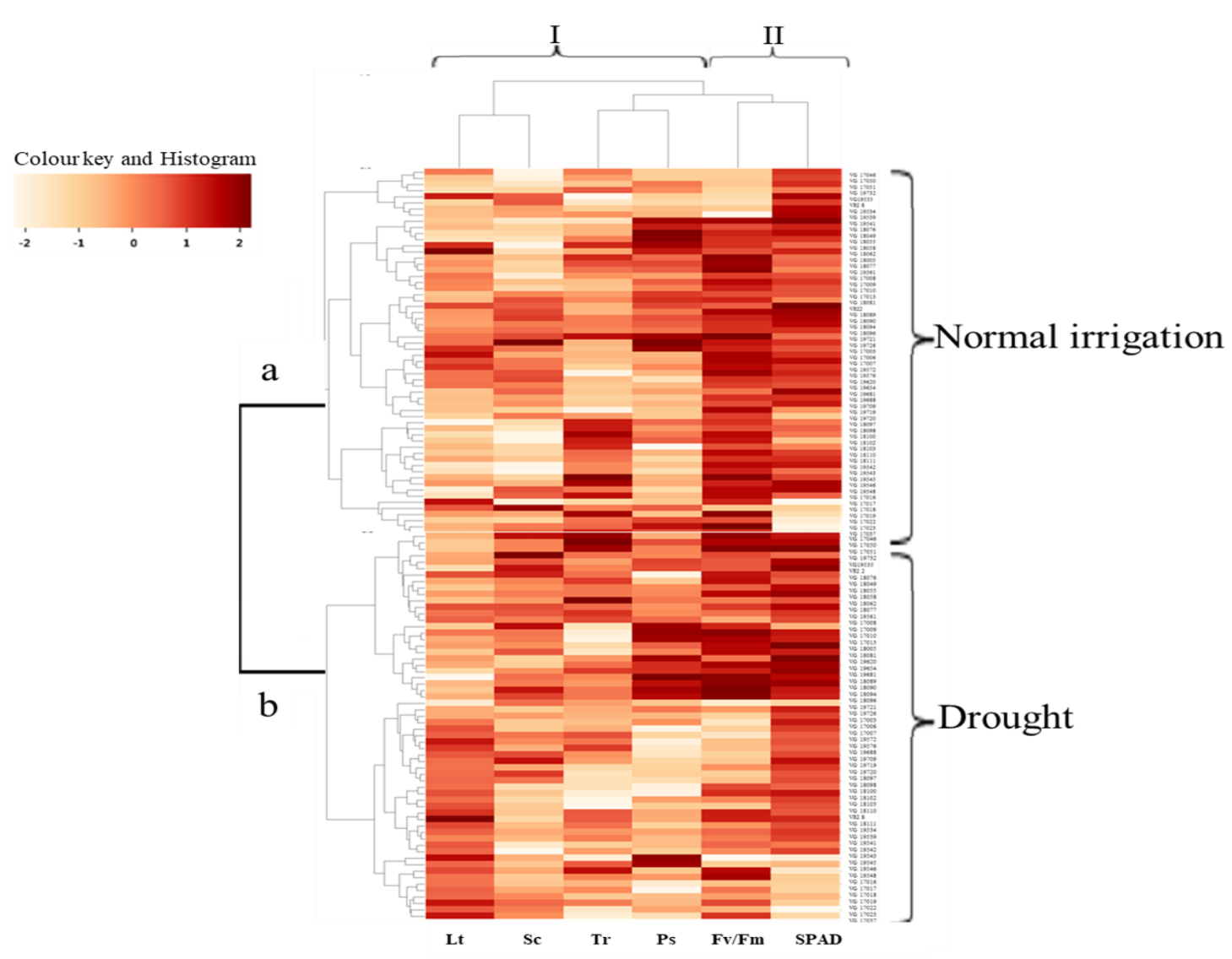

Fig. 4. Heat map and hierarchical clustering for gas exchange parameters and chlorophyll fluorescence (Ps- Photosynthetic rate, Sc- stomatal conductance, Lt -leaf temperature, $\mathrm{Tr}$-Ttranspiration rate, Fv /Fm-Chlorophyll fluorescence, $S P A D)$

matal conductance, transpiration rate, and chlorophyll fluorescence may be utilised as accurate drought resistance indices at the reproductive stage of groundnuts. Furthermore, drought-resistant cultivars VG 18005, VG 19709, VRI 2, and VG 18102, as well as drought-sensitive cultivars VG 17007, VG 17008, VG 19561, and VG 18096, may be employed as appropriate experimental materials to examine the mechanism of drought sensitivity in groundnut genotypes. Identifying the differences in cultivars' responses to drought stress can also aid in selecting a water management plan based on genotype. These findings lay the groundwork for a future study to decipher the molecular pathways underpinning Groundnut drought resistance.

\section{ACKNOWLEDGEMENTS}

The authors are thankful to the Department of Crop Physiology, Tamil Nadu Agricultural University, Coimbatore and Regional Research Station, Virudhachalam, Tamil Nadu.

\section{Conflict of interest}

The authors declare that they have no conflict of interest.

\section{REFERENCES}

1. Ahmed, S., Nawata, E., Hosokawa, M., Domae, Y. \& Sakuratani, T. (2002). Alterations in photosynthesis and some antioxidant enzymatic activities of mungbean subjected to waterlogging. Plant Science, 163(1), 117-123. https://doi.org/10.1016/S0168-9452(02)00080-8

2. Ashraf, M., Nawazish, S., \& Athar, H. U. R. (2007). Are chlorophyll fluorescence and photosynthetic capacity potential physiological determinants of drought tolerance in maize (Zea mays L.). Pakistan Journal of Botany, 39(4), 1123-1131.

3. Awal, M.A. and T. Ikeda. 2002. Recovery strategy following the imposition of episodic soil moisture deficit in stands of peanut (Arachis hypogea L.). Journal of Agronomy and Crop Science, 188: 185-192. https:// doi.org/10.1046/j.1439-037X.2002.00558.x

4. Barnabás, B., Jäger, K. \& Fehér, A. (2008). The effect of drought and heat stress on reproductive processes in cereals. Plant, cell \& environment, 31(1), 11-38. https:// doi.org/10.1111/j.1365-3040.2007.01727.x

5. Batra, N. G., Sharma, V., \& Kumari, N. (2014). Droughtinduced changes in chlorophyll fluorescence, photosynthetic pigments, and thylakoid membrane proteins of Vigna radiata. Journal of Plant Interactions, 9(1), 712721.https://doi.org/10.1080/17429145.2014.905801

6. Collins, C.N., Tardieu, F., Tuberosa, R. (2008). Quantitative trait loci and crop performance under abiotic stress: 
where do we stand? Plant Physiol. 147, 469-486.

7. Devi, M.J., Sinclair, T. R., Vadez, V. \& Krishnamurthy, L. (2009). Peanut genotypic variation in transpiration efficiency and decreased transpiration during progressive soil drying. Field Crops Research, 114(2), 280-285.

8. Dias, M.C. \& Brüggemann, W. (2010). Limitations of photosynthesis in Phaseolus vulgaris under drought stress: gas exchange, chlorophyll fluorescence and Calvin cycle enzymes. Photosynthetica, 48(1), 96-102. https:// doi.org/10.1007/s11099-010-0013-8

9. Djanaguiraman, M., Annie Sheeba, J., Durga Devi, D. \& Bangarusamy, U. (2009). Cotton leaf senescence can be delayed by nitrophenolate spray through enhanced antioxidant defence system. Journal of Agronomy and Crop Science, 195(3), 213-224. https://doi.org/10.1111/j.1439037X.2009.00360.x

10. Dulai, S. (2006). Effects of drought on photosynthetic parameters and heat stability of PSII in wheat and in Aegilops species originating from dry habitats. Acta Biologica Szegediensis, 50(1-2), 11-17.

11. Galle, A., Florez-Sarasa, I., Tomas, M., Pou, A., Medrano, H., Ribas-Carbo, M. \& Flexas, J. (2009). The role of mesophyll conductance during water stress and recovery in tobacco (Nicotiana sylvestris): acclimation or limitation?. Journal of Experimental Botany, 60(8), 2379-2390. https://doi.org/10.1093/jxb/erp071

12. Golabadi, M., Arzani, A.S. A. M., \& Maibody, S.M. (2006). Assessment of drought tolerance in segregating populations in durum wheat. African Journal of agricultural research, 1(5), 162-171.

13. Heinemann, A.B., Ramirez-Villegas, J., Stone, L. F. \& Didonet, A. D. (2017). Climate change determined drought stress profiles in rainfed common bean production systems in Brazil. Agricultural and forest Meteorology, 246,64 -77. https://doi.org/10.1016/j.agrformet.2017.06.005

14. Houghton, J. T., Ding, Y., Griggs, D. J., Noguer, M., Van Der Linden, P. J., Dai, X. \& Johnson, C. A. (2001). The scientific basis. Contribution of Working Group I to the Third Assessment Report of the Intergovernmental Panel on Climate Change, (IPCC), Geneva. https://doi.org/1 0.1016/j.bbabio.2012.02.037

15. Huseynova, I. M. (2012). Photosynthetic characteristics and enzymatic antioxidant capacity of leaves from wheat cultivars exposed to drought. Biochimica et Biophysica Acta (BBA)-Bioenergetics, 1817(8),1516-152.

16. Kalariya, K. A., Singh, A.L., Chakraborty, K., Zala, P.V. \& Patel, C.B. (2013). Photosynthetic characteristics of groundnut (Arachis hypogaea L.) under water deficit stress. Indian Journal of Plant Physiology, 18(2), 157-163.

17. Kauser, R., Athar, H. U.R. \& Ashraf, M. U. H. A. M. M. A D. (2006). Chlorophyll fluorescence: a potential indicator for rapid assessment of water stress tolerance in canola (Brassica napus L.). Pakistan Journal of Botany, 38(5 SPEC. ISS.), 1501-1509.

18. Khodarahmpour, Z., Choukan, R., Bihamta, M. R. \& MAJIDI, H. E. (2011). Determination of the best heat stress tolerance indices in maize (Zea mays L.) inbred lines and hybrids under Khuzestan province conditions.

19. Lauriano, J. A., Lidon, F.C., Carvalho, C.A., Campos, P. S. \& do Céu Matos, M. (2000). Drought effects on membrane lipids and photosynthetic activity in different peanut cultivars. Photosynthetica, 38(1), 7-12.
20. Lourtie, E., Bonnet, M., Bosschaert, L.(1995). New glyphosate screening technique by infrared thermometry. In: Fourth International Symposium on Adjuvants for Agrochemicals, Australia, pp. 297-302.

21. Maxwell, K. \& Johnson, G. N. (2000). Chlorophyll fluorescence-a practical guide. Journal of Experimental Botany, 51(345), 659-668

22. Miller, G. A. D., Suzuki, N., Ciftci $\square$ Yilmaz, S. U. L. T. A. N. \& Mittler, R. O. N. (2010). Reactive oxygen species homeostasis and signalling during drought and salinity stresses. Plant, cell \& environment, 33(4), 453-467. https:// doi.org/10.1111/j.1365-3040.2009.02041.x

23. Minolta, C. (1989). Manual for Chlorophyll meter SPAD502. Minolta Cameraco, Osaka, Japan.

24. Miyashita, K., S. Tanakamaru., T. Maitan and K. Kimura. (2005). Recovery responses of photosynthesis, transpiration and stomatal conductance in kidney bean following drought stress. Environ. Experimental Botany, 53(2), 205$214 \mathrm{https} / / /$ doi.org/10.1016/j.envexpbot.2004.03.015

25. Mohammadi, M., Karimizadeh, R. \& Abdipour, M. (2011). Evaluation of drought tolerance in bread wheat genotypes under dryland and supplemental irrigation conditions. Australian Journal of Crop Science, 5(4), 487-493.

26. Monje, O.A. and B. Bughree. 1992. Inherent limitation of non-destructive chlorophyll meters. A comparison of two types of meters. Horticulture Science, 27: 71-89. https:// doi.org/10.21273/HORTSCI.27.1.69

27. Nazari, L., \& Pakniyat, H. (2010). Assessment of drought tolerance in barley genotypes. J. Appl. Sci, 10(2), 151156.

28. Nouri, A., Etminan, A., Teixeira da Silva, J. A. \& Mohammadi, R. (2011). Assessment of yield, yield-related traits and drought tolerance of durum wheat genotypes (Triticum turjidum var. durum Desf.). Australian Journal of Crop Science, 5(1), 8-16.

29. Parameshwarappa, S. G., \& Salimath, P. M. (2010). Field screening of chickpea genotypes for drought resistance. Karnataka Journal of Agricultural Sciences, 21(1).

30. Prasad, P.V.V., P.Q. Craufurd and R.J. Summerfield (1999). Fruit number in relation to pollen production and viability in groundnut exposed to short episodes of heat stress. Annual Botany, 84: 381-386. https:// doi.org/10.1006/anbo.1999.0926

31. Reddy, T.Y., V.R. Reddy and V. Anbumozhi. 2003. Physiological responses of groundnut(Arachis hypogaea L.) to drought stress and its amelioration: A critical review. Plant Growth Regulations, 41: 75-88. https://doi.org/10.1556/ AAgr.51.2003.2.9

32. Savage, G. P., \& Keenan, J. I. (1994). In The groundnut crop: a scientific basis for improvement (ed): J. Smart.

33. Sita, K., Sehgal, A., Kumar, J., Kumar, S., Singh, S., Siddique, K. H. \& Nayyar, H. (2017). Identification of hightemperature tolerant lentil (Lens culinaris Medik.) genotypes through leaf and pollen traits. Frontiers in Plant Science, 8, 744. https://doi.org/10.3389/fpls.2017.00744

34. Sun, J., Luo, H., Fu, J., \& Huang, B. (2013). Classification of genetic variation for drought tolerance in Tall Fescue using physiological traits and molecular markers. Crop Science, 53(2), 647-654. https://doi.org/10.2135/ cropsci2012.05.0315

35. Todaka, D., Shinozaki, K., \& Yamaguchi-Shinozaki, K. (2015). Recent advances in the dissection of drought- 
stress regulatory networks and strategies for development of drought-tolerant transgenic rice plants. Frontiers in Plant Science, 6, 84. https://doi.org/10.3389/ fpls.2015.00084

36. Vurayai, R.V. Emongor and B. Moseki. (2010). Physiological Responses of Bambara Groundnut (Vigna subterranea L. Verdc) to Short Periods of Water Stress During Different Developmental Stages. Asian Journal of Agricultural Sciences, 3(1): 37-43

37. Wheeler, T.R., Craufurd, P. Q., Ellis, R. H., Porter, J. R. \& Prasad, P. V. (2000). Temperature variability and the yield of annual crops. Agriculture, Ecosystems \& Environment, 82(1-3), 159-167. https://doi.org/10.1016/S0167-8809(00) 00224-3

38. Yolcu, S., Alavilli, H., Ganesh, P., Panigrahy, M., \& Song, K. (2021). Salt and Drought Stress Responses in Cultivated Beets (Beta vulgaris L.) and Wild Beet (Beta maritima
L.). Plants, 10(9), 1843. https://doi.org/10.3390/ plants 10091843

39. Zandalinas, S. I., Balfagón, D., Arbona, V. \& GómezCadenas, A. (2017). Modulation of antioxidant defense system is associated with combined drought and heat stress tolerance in citrus. Frontiers in Plant Science, 8, 953. https://doi.org/10.3389/fpls.2017.00953

40. Zlatev, Z. (2009). Drought-induced changes in chlorophyll fluorescence of young wheat plants. Biotechnology \& Biotechnological Equipment, 23(sup1), 438-441. https:// doi.org/10.1080/13102818.2009.10818458

41. Zlatev, Z. S., \& Yordanov, I. T. (2004). Effects of soil drought on photosynthesis and chlorophyll fluorescence in bean plants. Bulg. J. Plant Physiol, 30(3-4), 3-18.

42. Thomas, H., Ougham, H. J., Wagstaff, C. \& Stead, A. D. (2003). Defining senescence and death. Journal of Experimental Botany, 54(385), 1127-1132. 